\title{
Design and Evaluation of a new Banking Interface System Based on Wireless Networks in Referral Customers to the Bank to Increase Customer Satisfaction
}

\author{
Reza Mohamaddoust \\ Department of IT Engineering, Payame Noor University (PNU), IRAN \\ E-mail:PNU1392@yahoo.com
}

\begin{abstract}
Electronic banking reduced customers referring to the bank in person, but still some banking process needs the customer presence. This matter is wasting customers' time and it can cause overhead costs for banks. Therefore, this study is introducing a banking system interfaces based on wireless networks which will be reduce customers' in-person visits. These systems reduce the waiting time of customers in the personal referrals and increase employees' productivity. It uses the structures of the wireless communication system based on wireless sensor networks or local wireless networks .In its simplest form, this system is implemented as mobile phone software. The results of the assessment show that this system also reduces customer waiting time. Reduce the overhead costs of banks Significantly reduce the amount of manual data entry by employees, accelerate service delivery and maximize coordination among employees more accurate prediction of customer waiting time and the reduction of human errors. The results of comparing these kinds of systems show that the proposed system is reducing common weaknesses that are used in current methods in the customer's personal referrals to the bank.
\end{abstract}

Keywords: Wireless Sensor Networks, Systems Interface Banking, E-Banking.

\section{INTRODUCTION}

Nowadays, a variety of wireless networks are used in several applications. The use of wireless networks for energy management and control systems, including automated energy control systems [1-7], the control system and environmental monitoring [8] and smart systems such as intelligent building [9] is in development.

Expansion of economic activities has led banks to compete for providing better services to customers. The importance of this competition and advances in information and communication technology has led to banks overtake each other in this field. In recent years, expansion of the electronic banking services has led to expansion of the customer satisfaction and also, increased the availability of banking for customers. Therefore, it reduced urban traffic and environmental pollution. Also, development of ebanking has led to using of the banking services in every place and time.
Use of software and hardware equipments in the fast networks for processing a large number of realtime transactions has led to accelerating integration service banking operations. Using of ATMs, internet banking and so on are signs of the importance of the competition over the quality of services. Since the importance of customer satisfaction considered as a key parameter for banks, many researchers have studied to model the satisfaction of the customers same as [10-11].

Some banking services are still required to visit clients in person. Operations such as depositing cash in a bank account, cash a check, Payment Bonds done and so on only by calling for banks. Refer client to the bank has advantages and disadvantages, some of them are mentioned below.

The benefits of customers' in-person reference to the bank are: authenticate of account holders by bank employees (checking the customer identification) and access to different levels of employees for information interchange. 
On the other hand, long waiting time to receive services (even with dispenser machine), filling up different types of form for several times, linger to get answers to questions due to the banks' rush, the increase of employees' working pressure because of customers' in-person visits, service quality reduction and increase of the risk of employees' error, the increase of banks' overhead costs because of high consumption of consumable items (pens, paper, etc.) in customers' personal presence. Failure to use or difficulty of banking operations for the blind are some disadvantages that reduce the customer satisfaction on a personal visit to the bank.

Therefore a banking interface system has been designed in this study based on wireless networks in customers' personal referrals. The system has been named called BOIS (Banking Operation Interface System) and it has the following advantages:

- Reduce the customers' waiting time in personal reference.

- Reduction of banks' employee fatigue due to elimination of data entry operations

- Increase security in banking operations by using fingerprint and Customer image

- Coordination increase between banks' employees with different levels

- Accelerated in banking Operations

- The blind's ability to use banking operations in a secure way

- Responding to customer inquiries

- Initial validation of customers' input

- Reduction of human errors in filling out forms

- The ability to estimate customers' waiting time more precision

The above features increase customer satisfaction and the efficiency of employees through customers' in-person visits. The study will be introducing the BOIS and the various component descriptions in the second part. The system performance has been explored as well. Finally, the performance of BOIS and current methods used in banks were compared with a designed scenario.

\section{INTRODUCTION TO BIOS}

The system components and then the system performance will be expressed for the introduction of the system. The system components are connected to each other using wireless protocols. BOIS components include:

\subsection{Customer Data Entry Interface}

This device is a customized personal digital assistant (PDA).In fact, this device is where customers enter login information and by a graphical software and all related banking forms designed in and used. In brief the device is the customer interface. In order to increase the security of banking operations, customer interface can have more features like a fingerprint module or camera. This interface uses the RFID tag to declare the exit of these devices out of the bank. Customer interface has a wireless transmitter and a receiver (Wi-Fi, Bluetooth or ZigBee).

\subsection{Customer Interface's Information Receiver Software}

The software receives the data that has been sent from the client interface and displays them on staff's computers via the local control interface. This software can be integrated with the bank's database software. It is called as admin interface.

In the simplest implementation of the system, the customer information input interface can be considered as a mobile software which is in communication with the local control interfaces via Bluetooth or local wireless. This method can reduce the costs of finished BOIS and to be considered as a model of this system.

\section{SYSTEM FUNCTION}

First of all, a banking service will be selected by the customer through the client interface and related forms will be displayed. After filling out the forms and final approval of information from the customer in the customer interface, the data filled in the form will be sent to the local controller interface and he will send the relevant information interface employees' software. When it reaches to the customers, the bank employees will review the received information and if there is no problem, 
they will do the verification and necessary action (such as pay, particularly the cheque, etc.).

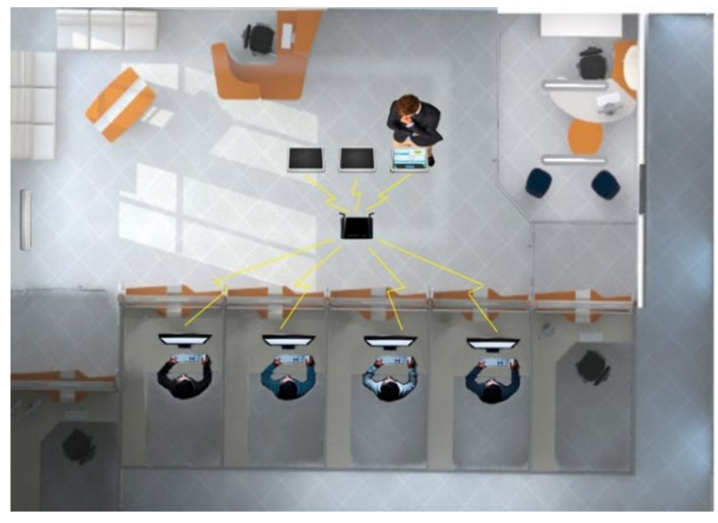

Fig. 1. Scheme of this system

In fact, at this stage, the employee with the least amount of data entry (information which has been sent before) performs operations on physical interaction and authentication. In the following several aspects of the functions of this system are mentioned. Figure 1 shows a view of this system.

Because of the existence of special rules and conditions in most of the banking operations more than one employee should perform and monitor this operation. For example, the head of the branch should be informed immediately in order to withdrawal of huge amounts, or when amounts are above the threshold, the information also will be sent to fund employee, the head of the branch, another hierarchy and those who are in charge.

Validation of data entered and automated production of date and time, also converting numbers to letters or filling up of all personal and relevant information about customers automatically by receiving the customer number are the positive aspects of this system.

Being useful in advertising and marketing is another functional aspect of the system. Notice of new services, security alerts or cultural messages for various occasions on customer interface device screen can be very valuable as well.

The customer interface device can be used easily by blinds with the voice maker software. Customer interface devices using the voice maker software can be easily used by the blind and these people can verify various types of forms by using fingerprint and if needed sign hard copy forms whenever they refer to the fund employee in the bank.

In many cases, bursar should consider and knowing the amount of cash holdings of fund employees to provide enough cash in case of decrease in cash that this action also needs time consuming and somehow it might increase the waiting time for customers. By using the BIOS, the local control interface can find out the desired amount of customers who are waiting and have filled out forms periodically and do the necessary actions faster in case of any decrease in cash amount.

With this system waiting time for customers to get served at banks will be calculated much more accurate than traditional methods compare to electronic queuing system or ticket dispenser machine. When a new user enters the bank the waiting time is calculated according to the operations that clients have asked before. For example, we assume that at the arrival time of a customer at the bank, 10 people have got number ahead of him. The average waiting time for each individual has been multiplied by 10 on older systems. If the waiting time approximately considered as two minutes per individual, the waiting period will be 20 minutes. With the use of BOIS customers can record and register their different operations. For example, from the 10 customers in front of the queue, 5 customers have requested for two banking operations and one customer wants to deposit a large sum of cash and the other four clients are waiting for one simple operation which is cash withdrawal. The waiting time for new customer will be calculated based on average waiting time of each banking operation which is much more accurate than the traditional method.

Request of reviewing the customer account can be sent in a message to the local interface controller by adding the module card reader to the customer interface and close the customer's credit cards to that. Then the message will be sent to the server (or a system administrator) and customer account information will be delivered to the customer interface as a response (by local interface). Customers are be able to view their account information and take the right decision by this way, thus there is no necessity of entering customer information and it will no longer be required and the device will be declared all these messages and information to the customers. The system will also display the current status of the workflow to the client to pursue the administrative process works. If a customer has applied for a loan, he can get informed of hiding request progression via the customer interface.

This case can be considered as the effects of this system in the expediting of banking operations when the number of customers has entered their desired operations in the user interface. These requests, for example includes two types of operations, one of them is about the request of 
R. Mohamaddoust / International Journal of Computer Networks and Communications Security, 2 (10), October 2014

coded cheque and the other one is the request of transferring money. There are three customers for the first type which requires the approval and signature of the head of the branch. The employee can prevent the repeat and recurrence of such acts by referring once only to the chief of the branch for the all three customers (in plain English, performing similar operations in parallel).

\section{EVALUATION OF SYSTEM PERFORMANCE}

To evaluate the performance of the system, parameters of one scenario have been considered in Table 1. Data collection has been conducted at Karafarin Bank in Karaj Branch. Serve number one, such as depositing money into government accounts (fines or taxes), second serves like request for interbank cheque and third example of serving is opening bank account for customers. Data entry of the above three services, will respectively take 1 , 2 and 8 minutes of the clerk's time. The scenario in the last column of table 1 is intended to evaluate the initialization of parameters. In this scenario, 20 customers are waiting for service, and an employee is providing services.

Table 1: The parameters which are used to evaluate BOIS

\begin{tabular}{|c|c|c|}
\hline Row & Description of Parameters & Values \\
\hline 1 & The number of active employees & 1 \\
\hline 2 & The number of waiting customers & 20 \\
\hline 3 & Average of service time 1 & 2 minutes \\
\hline 4 & Average of service time 2 & 4 minutes \\
\hline 5 & Average of service time 3 & 10 minutes \\
\hline
\end{tabular}

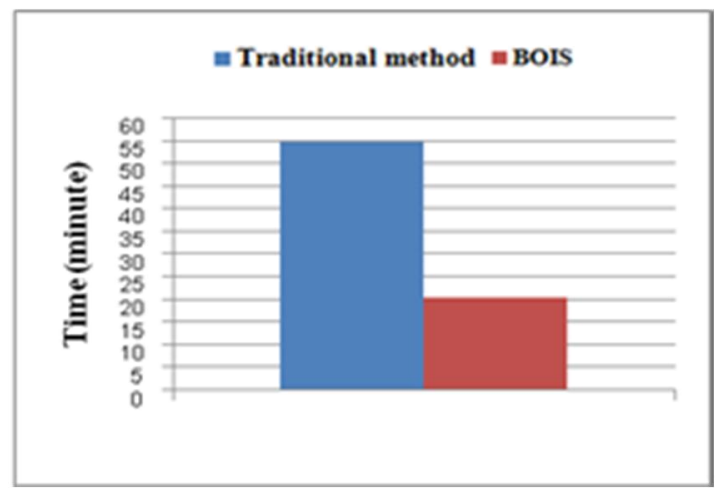

Fig. 2. Comparison of the mean waiting time for customers to receive services according to the scenario in table

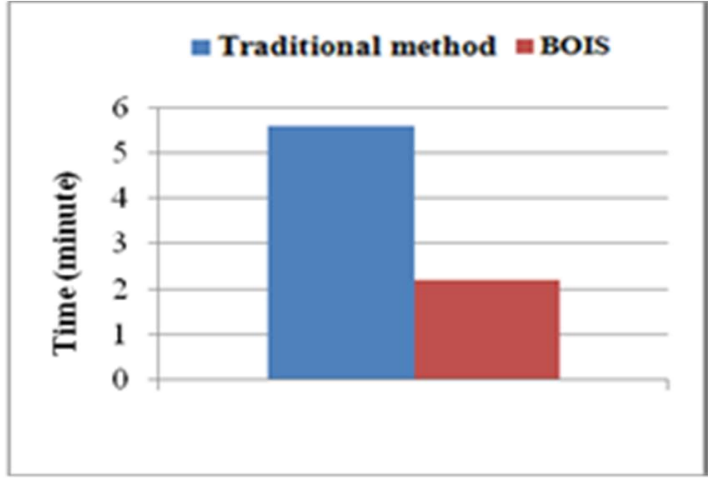

Fig. 3. Comparison of the mean time of service according to the scenario in table 1

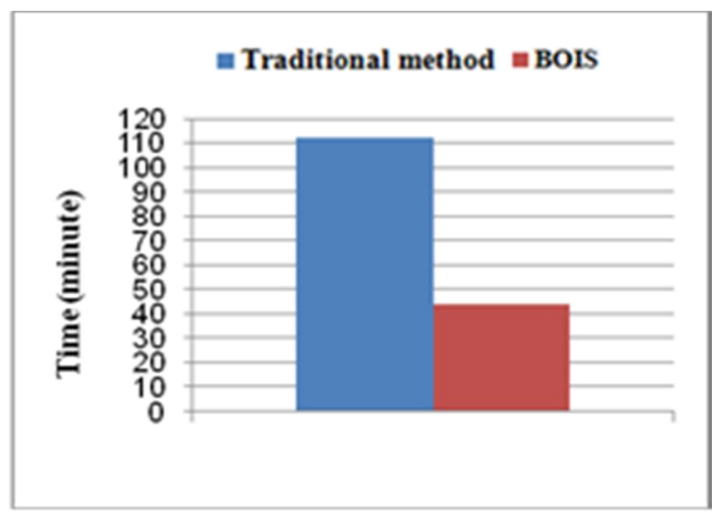

Fig. 4. Comparison of the time that takes for all clients to receive services according to the scenario in table 1

Figure 2 compares the waiting time of customers in traditional banking methods (traditional method) and the method based on BOIS.

Figure 3 shows these two methods based on the average length of serving each client by fund's employees.

Figure 4 shows the amount of time that will be taken till all customers receive the service. As seen the proposed method has made remarkable improvements in all these cases.

The results have shown that an effective system for aligning employee performance, reduce the time serving time. These results are applicable for different scenarios, but because of the obvious superiority of this system over the traditional system it has been limited to the same scenario. 
R. Mohamaddoust / International Journal of Computer Networks and Communications Security, 2 (10), October 2014

\section{CONCLUSION}

In this study, a banking system based on the wireless network interface is provided which is helping to resolve many of the problems found in the customer reference in person to the banks. This increases customer satisfaction and the performance of employees. Future research in this field can customize these systems in agencies and other entities which regular attendance is a necessity there. Also adding more restrictions, such as human error or network dysfunctions increase accuracy in predicting the waiting time for customers.

\section{ACKNOWLEDGEMENTS}

I would like to thanks Payame Noor University (PNU) for financial support on this research.

\section{REFERENCES}

[1] F. O'Reilly, and J. Buckley, "Use of Wireless Sensor Networks for Fluorescent Lighting Control with Daylight Substitution", Proceeding of Workshop on Real-World Wireless Sensor Networks (REANWSN), Sweden, June 20-21, 2005.

[2] H. Park, M. B. Srivastava, and J. Burke, "Design and Implementation of a Wireless Sensor Network for Intelligent Light Control", Proceedings of 6th International Symposium on Information Processing in Sensor Networks, $\neg$-IPSN'2007, Cambridge, MA, USA, April 25-27, 2007.

[3] Y. J. Wen, J. Granderson, and A. M. Agogino, "Towards Embedded Wireless-Networked Intelligent Daylighting Systems for Commercial Buildings", Proceedings of IEEE International Conference on Sensor Networks, Ubiquitous, and Trustworthy Computing, SUTC'2006, Taiwan, June 5-7, 2006.

[4] M. S. Pan, L. W. Yeh, Y. A. Chen, Y. H. Lin, and Y. C. Tseng, "wsn-based intelligent light control system considering user activities and profiles", IEEE Sens. J., 2008, pp. 1710-1721.

[5] M. Abduh, and M. A. Omar, "Islamic Banking and Economic Growth: the Indonesian Experience", International Journal of Islamic Middle Eastern Finance and Management, Vol. 5, No. 1, Apr. 2012, pp. 35-47.

[6] W. Y. Lun, Y. L. Che, W. K. Chi, C. T. Yu, and W. Y. Chih, "Autonomous light control by wireless sensor and actuator networks", IEEE Sens. J., 2010, 10, pp. 1029-1041.

[7] V. Singhvi, A. Krause, C. Guestrin, J. H. Garrett, and H. S. Matthews, "Intelligent Light
Control Using Sensor Networks", In Proceedings of ACM International Conference Embedded Networked Sensor Systems, SenSys'2005, San Diego, CA, USA, November 2-4, 2005, pp. 218-229.

[8] R. Mohamaddoust, A. T. Haghighat, M. J. Motahari Sharif, and N. Capanni, "A Novel Design of an Automatic Lighting Control System for a Wireless Sensor Network with Increased Sensor Lifetime and Reduced Sensor Numbers", Sensors, 2011, 11, pp. 8933-8952.

[9] A. Mainwaring, J. Polastre, R. Szewczyk, D. Culler, and J. Anderson, "Wireless Sensor Networks for Habitat Monitoring”, In Proceedings of the 1st ACM Workshop on Wireless Sensor Networks and Applications, Atlanta, 2002.

[10]D. Snoonian, "Smart Buildings", IEEE Spectrum, Vol. 40, No. 8, 2003, pp. 18-23.

[11] M. Amin, and Z. Isa, "An Examination of the Relationship Between Service Quality Perception and Customer Satisfaction: A SEM Approach Towards Malaysian Islamic Banking", International Journal of Islamic Middle Eastern Finance and Management, Vol. 1, No. 3, 2008, pp. 191-209.

[12]J. G. Proakis, and D. G. Manolakis, "Digital Signal Processing Principles, Algorithms and Applications", New York, Macmillan, 1992.

\section{AUTHOR PROFILES:}

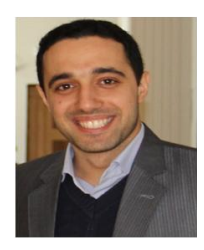

Reza Mohamaddoust received his MSc in IT in 2010. He is currently faculty of Information and Communication Technology department (Payame Noor University- Alborz Province). Mohamaddoust research interests include Computer Networks, Information Technology, Enterprise Architecture, and Information Systems. 